\title{
Analysis of model sheet pile walls with plastic hinges
}

\author{
P. J. BOURNE-WEBB*, D. M. POTTS†, D. KÖNIG $\ddagger$ and D. ROWBOTTOM
}

As part of a wider project investigating the implications of Eurocode 3, Design of steel structures - Part 5: Piling, centrifuge testing of model sheet pile walls and numerical back-analysis were undertaken. The aims of the study were to examine the effect of plastic hinging on embedded retaining wall response, and to verify calculation methods for use in wider generic calculations. Physical modelling of an anchored wall embedded in dry sand was undertaken. In some of the tests a hinge zone was introduced into the wall in order to reproduce a kinematic mechanism similar to that associated with plastic hinge formation. Finite-element calculations were undertaken using Lade's double-hardening cap model to represent the behaviour of the sand. The analyses generally yielded good accord with the test results in many aspects of the wall behaviour. In terms of the aims of the testing, the study of the effect of plastic hinging was not realistically captured, because the hinge zone was present from the outset of the test, allowing greater than expected earth pressure redistribution, and because the moment-curvature characteristic of the notched wall did not reproduce the buckling effects seen in the plastic bending response of steel sheet piles. On the other hand, the satisfactory agreement between the test observations and the numerical predictions gave confidence in the use of the calculation model for further generic calculations using realistic steel sheet pile moment-plastic curvature characteristics.

KEYWORDS: centrifuge modelling; limit state design/analysis; numerical modelling; sheet piles and cofferdams; standards
Dans le cadre d'un projet plus général de recherche des implications de la norme Eurocode $3: 5^{\text {ème }}$ partie - Pieux d'acier, on a effectué des épreuves centrifuges sur un modèle de paroi en palplanches ainsi qu'une rétro-analyse numérique. L'objet de l'étude était d'examiner l'effet de charnières en matière plastique sur la réaction de murs de soutènement encastrés et de vérifier des méthodes de calcul pouvant être appliquées dans des calculs génériques plus larges. On a effectué la modélisation physique d'un mur ancré dans du sable sec. Dans un certain nombre d'essais, on a introduit une zone à charnière dans la paroi, afin de reproduire un mécanisme cinématique similaire à celui que l'on associe avec une formation à charnière en matière plastique. On a effectué des calculs aux éléments finis en utilisant le modèle à double chapeau de durcissement, proposé par Lade, pour représenter le comportement du sable. D'une manière générale, les résultats produits par l'analyse sont en accord avec les résultats d'essais pour de nombreux aspects du comportement du mur. Sur le plan de l'objet des essais, l'étude de l'effet des charnières en matière plastique n'a pas pu être capturée de façon réaliste, du fait que la zone de la charnière était présente dès le début de l'essai, en permettant ainsi une redistribution de la pression de la terre plus élevée que prévu, et que la caractéristique de moment-courbure du mur crénelé ne reproduisait pas les phénomènes de gondolage relevés dans la réaction à flexion plastique des palplanches d'acier. Par contre, la correspondance satisfaisante entre les observations effectuées au cours des essais et les prédictions numériques fournissaient une certaine assurance dans l'utilisation du modèle de calcul pour d'autres calculs génériques utilisant des caractéristiques réalistes de moment /flexion plastique des palplanches d'acier.

\section{INTRODUCTION}

In 2010 the Eurocode system came into force in the UK and throughout Europe. These codes allow the use of plastic design for some sheet pile sections; for appropriate sections, the cross-section may be fully plastic with associated plastic rotation.

As a consequence of the introduction of the Eurocodes and the possibility of using plastic design methods, steel manufacturers were very interested in defining the means by which this may be undertaken safely when using steel sheet pile products. The research arms of the major European steel manufacturers initiated a joint project with the aim of developing a design tool utilising the limit state concepts being introduced in Eurocode 3, Design of steel structures Part 5: Piling. In particular, the project was intended to

Manuscript received 7 May 2009; revised manuscript accepted 12 January 2010. Published online ahead of print 19 July 2010.

Discussion on this paper closes on 1 November 2011, for further details see p. ii.

* Independent Geotechnical Engineer, Lisbon, Portugal

$\uparrow$ Imperial College, London, UK.

$\$$ Ruhr-Universität, Bochum, Germany.

$\S$ Corus Construction Services and Development, Scunthorpe, UK. develop a means for analysing structures at the ultimate limit state (ULS), incorporating the effects of plasticity in both the soil and the steel sheet pile (SSP) section.

As part of this project, both physical and numerical modelling were undertaken. Centrifuge tests at 1:30 scale were carried out that were intended to be representative of typical design situations. Testing of the model retaining walls was undertaken in Germany at Ruhr-Universität Bochum in cooperation with the geotechnics group at BU Wuppertal and the RWTH Institute of Steel Construction, Aachen. Numerical calculations using the finite-element method were undertaken at Imperial College, London.

In this paper, summary details of the physical modelling of the walls are presented, and then the numerical analyses undertaken are outlined. Finally, the numerical predictions are compared with the test observations and are discussed in terms of the study's aims.

\section{CENTRIFUGE MODEL TESTS}

A total of 10 centrifuge tests have been performed at the Institute of Geotechnical Engineering and Soil Mechanics of Ruhr-Universität Bochum, Germany. Seven of these simulated embedded walls with a single row of anchors, and the 
remaining three simulated two anchor levels. Only four of the single-anchor tests (SPWFG 13 to 16; Table 1) are presented in detail here; three earlier tests were trials to ensure that the modelling technique used was practicable, and to gain insight into where on the wall the hinge zone should be located.

The intention of the tests was to measure the earth pressure acting on a wall in dry sand, forming a kinematic mechanism associated with plastic hinge formation while taking into account realistic construction processes. A key assumption made in the design of these tests was that the earth pressure (and hence the internal wall forces) acting on the wall system at the end of the test, when a hinge zone was present from the start of the test, would be representative of the pressures on a wall that had undergone elastic deformation prior to hinge formation at some later stage of the excavation process close to the end of the test. While this assumption was perhaps an oversimplification, it was deemed acceptable in order to facilitate the testing programme. The results obtained from this testing were then used as a means for verifying available calculation models.

\section{Summary details}

The geometry of the centrifuge strongbox and the location of instrumentation are shown schematically in Fig. 1. Instrumentation included linear variable displacement transducers (LVDTs) that were used to measure wall movement, load transducers on each of the anchor cables, and strain gauges that were used to evaluate the bending moment distribution on the wall centreline (König, 2002).

Each test specimen was formed in the strongbox by applying a sandwich of greased plastic sheeting to the sidewalls and then raining in the sand. During the placement of the sand, the process was halted at appropriate stages to allow the wall, instrumentation and anchor cables to be placed.

The anchor system comprised wire strands that ran from a waling beam on the wall, inside a tube, through the sand, passing through the rear wall of the strongbox and onto an axle mechanism. Between the two anchor cables a toothed wheel was fitted to the axle, over which ran a chain that was attached to a counterweight at one end and a container at the other. The container could be filled with fluid to simulate anchor prestressing while the test was in flight. There was a brake system to allow the anchors to be fixed, and a force transducer to measure each of the anchor loads.

In order to achieve exact similitude between model and prototype, impracticably thin steel wall sections would be required, and therefore a compromise was needed between the requirements for handling of the wall element and achieving wall plasticity. Several alternative options for modelling the scaled response of an SSP wall in the centrifuge test were considered, including composite aluminium sections, voided sections and notched sections (Table 2). Because of problems in achieving the correct plastic bending moment and plastic rotation capacity using

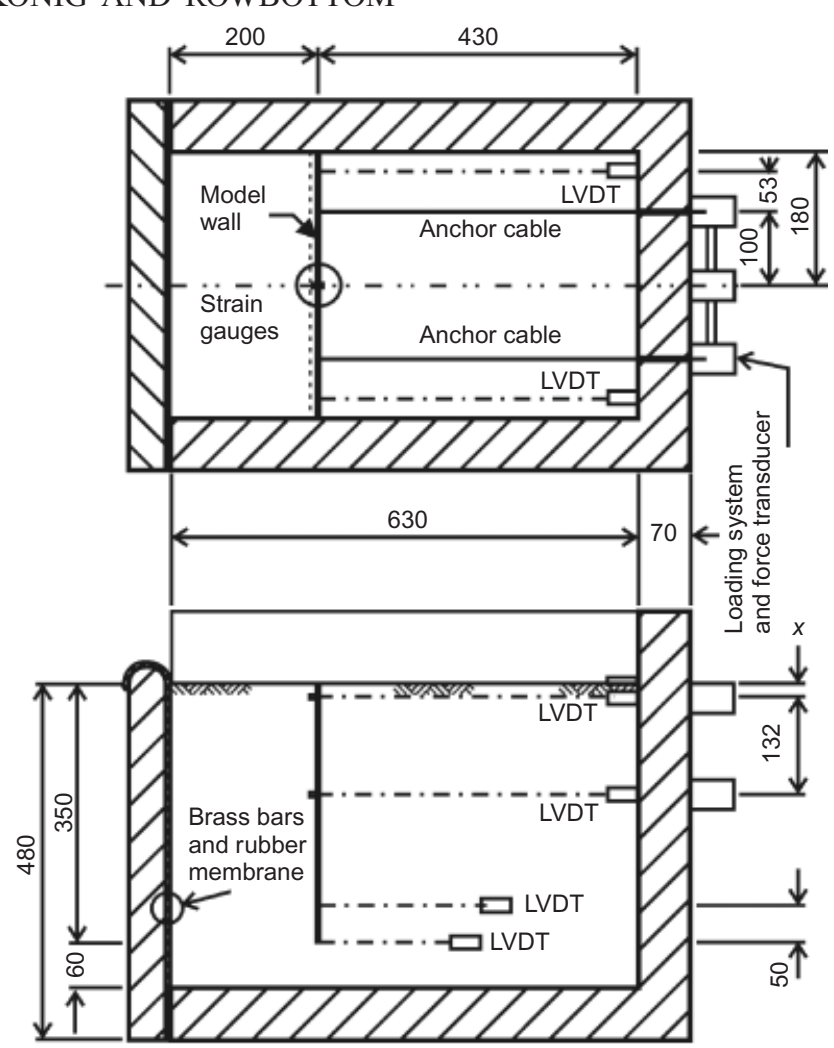

Fig. 1. Layout of centrifuge strongbox (dimension $x=40 \mathrm{~mm}$ for SPWFG 11 to $14 ; 18 \mathrm{~mm}$ for SPWFG 15 to 19 )

composite or voided sections, a notched section was selected as the most suitable for the centrifuge-testing programme. This was not the ideal choice, as the 'hinge zone' in this model wall strain-hardens as plastic bending strains increase, without the loss of section bending capacity due to buckling that is associated with real SSP sections.

When in flight, excavation was simulated by lowering the front wall of the strongbox and using a scraper mechanism to remove sand from in front of the model sheet pile wall. Excavation proceeded until the wall system exhibited instability.

The sequencing of each single anchor wall test was broadly similar following preparation of the test specimen. First, the strongbox was accelerated to $30 \mathrm{~g}$ and at the same time a small initial preload was applied to the anchors. Then excavation proceeded to just below the anchor level, the full preload was applied, and the anchors were locked off. Following this, the excavation was progressed until geotechnical failure of the wall system developed.

Data obtained from the tests included a bending strain envelope, from which the bending moment distribution on the centreline of the wall was inferred (Fig. 2), anchor loads (Fig. 3), and displacements at the level of the wall toe, the hinge zone (when present), anchor level and the head of the

Table 1. Summary details for centrifuge tests (model dimensions)

\begin{tabular}{l|c|c|c|c|c}
\hline \multirow{2}{*}{ Run ID } & \multicolumn{3}{|c|}{ Wall geometry: $\mathrm{m}$} & \multicolumn{2}{c}{ Anchor details } \\
\cline { 2 - 5 } & Length & Thickness & Hinge depth & No. & Depth: $\mathrm{m}$ \\
\hline SPWFG 13 & 0.250 & 0.00255 & $\mathrm{n} / \mathrm{a}$ & 1 & 0.040 \\
SPWFG 14 & $0 \cdot 250$ & 0.0030 & $0 \cdot 167$ & 1 & 0.040 \\
SPWFG 15 & $0 \cdot 250$ & 0.0030 & $0 \cdot 167$ & 1 & 0.018 \\
SPWFG 16 & 0.250 & 0.0030 & 0.167 & 1 & 0.018 \\
\hline
\end{tabular}


Table 2. Model wall types considered for use in tests

\begin{tabular}{|c|c|c|c|}
\hline $\begin{array}{r}\text { Type } 1 \text { (a) } \\
\text { (b) } \\
\text { (c) }\end{array}$ & $\begin{array}{l}\text { Plain } \mathrm{Al}^{*} \text { plate } \\
\text { Single notch } \\
\text { Double notch }\end{array}$ & $\begin{array}{l}2.55 \mathrm{~mm} \mathrm{Al} \text { plate } \\
3 \mathrm{~mm} \mathrm{Al} \text { plate, reduced to } 0.85 \mathrm{~mm} \text { in } 1.5 \mathrm{~mm} \text { wide } \\
\text { hinge zone }\end{array}$ & $\begin{array}{l}\text { Target plastic moment achieved, but resistance } \\
\text { does not soften; it hardens slightly }\end{array}$ \\
\hline Type 2 & Voided plate & $\begin{array}{l}\text { Plain sheet with void drilled to leave thin walls to } \\
\text { ensure peak resistance followed by softening due to } \\
\text { buckling }\end{array}$ & $\begin{array}{l}\text { Good accord with SSP, but affected by strain- } \\
\text { hardening caused during formation of void }\end{array}$ \\
\hline Type 3 & Alucobond & $\begin{array}{l}\text { Two } 0.5 \mathrm{~mm} \text { Al plates either side of a } 3 \mathrm{~mm} \\
\text { polyethylene sheet }\end{array}$ & $\begin{array}{l}\text { Too high a moment and plastic rotation capacity } \\
\text { with creep affecting results }\end{array}$ \\
\hline Type 4 & Alucore & $\begin{array}{l}\text { Two Al plates, } 0.7 \mathrm{~mm} \text { and } 1.05 \mathrm{~mm} \text { thick, } \\
\text { sandwiching } 4.35 \mathrm{~mm} \mathrm{Al} \text { honeycomb structure }\end{array}$ & $\begin{array}{l}\text { Too stiff in bending, with little or no plastic } \\
\text { rotation before collapse }\end{array}$ \\
\hline
\end{tabular}

${ }^{*} \mathrm{Al}=$ aluminium.

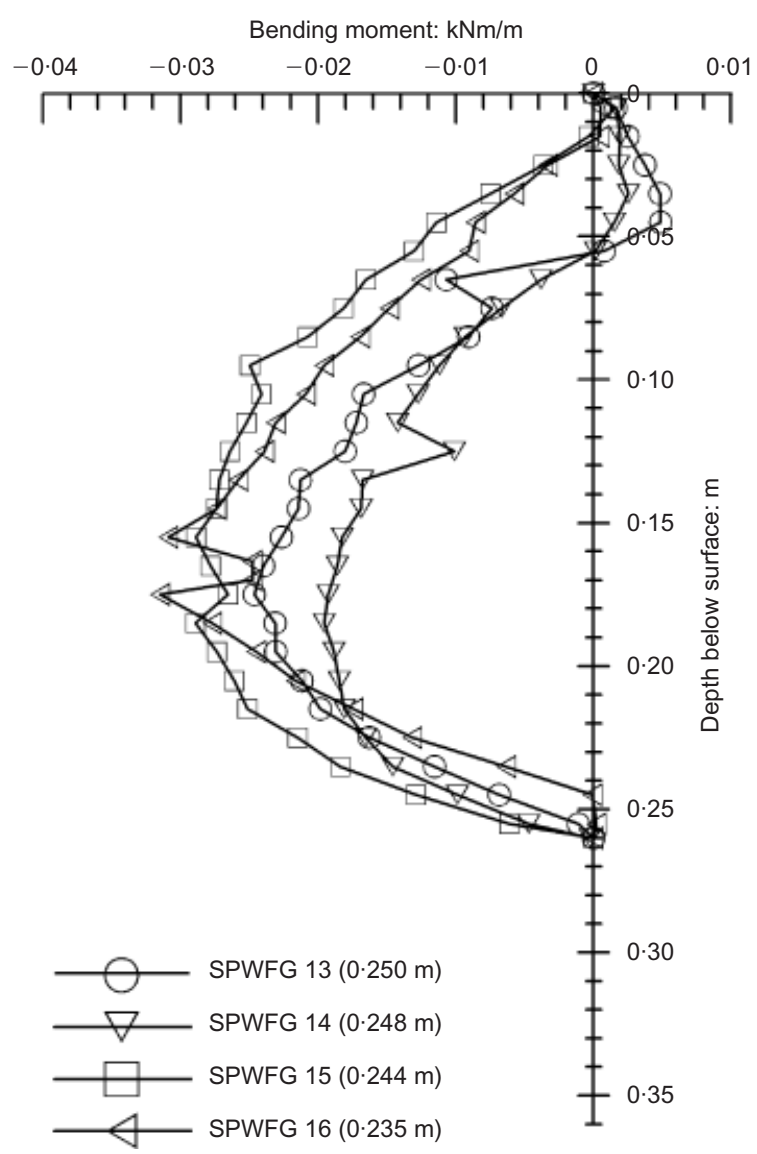

Fig. 2. Moment envelopes inferred from tests (at model scale)

wall, at an offset of about $140 \mathrm{~mm}$ from the centreline of the model strongbox. The deflected wall profile (see Figs 10-13 below) and the earth pressure distributions could also be inferred from the bending moment profile, by double integration and double differentiation respectively.

Equivalent linear effective stiffness values for each anchor were assessed from the load-displacement response measured in each test (Fig. 3 and Table 3). It can be seen that the effective anchor stiffness values changed from test to test (Table 3), as well as during each test (Fig. 3). The values are also much smaller than the theoretical values obtained from the relationship for stiffness, $E A / L$, where $E$ is Young's modulus for the anchor tie, $A$ is the tie cross-section area, and $L$ is the length of the tie between the wall and the anchor point at the rear of the strongbox.

The data provided for comparison with the numerical calculations relate to the last, stable stage of the centrifuge

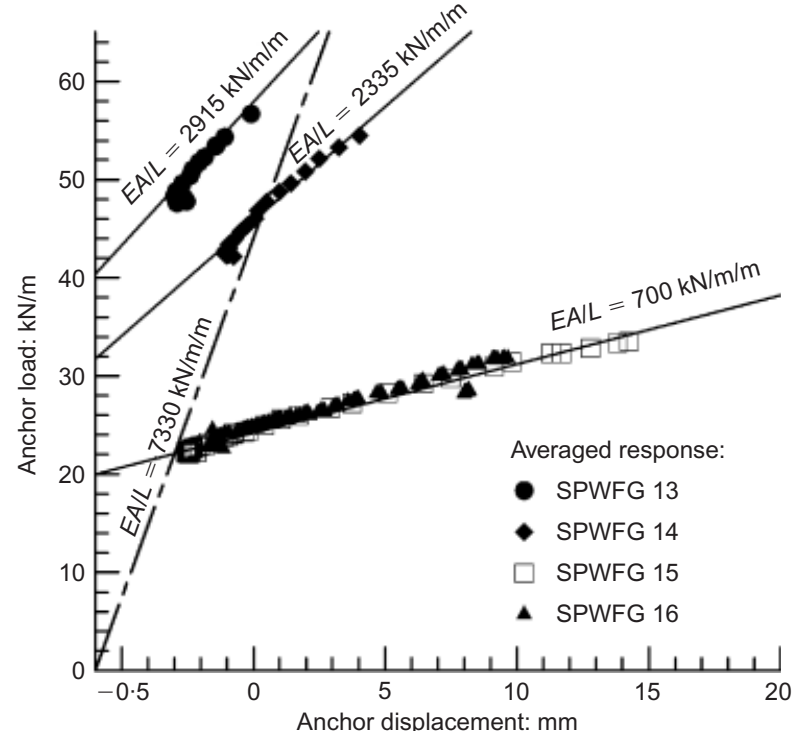

Fig. 3. Variation in anchor stiffness during testing (at prototype scale)

tests. Also, because of the modifications made in an attempt to force plasticity to develop in the hinge zone, there were no repeat tests using exactly the same configuration that would have allowed the repeatability of the test results to be confirmed.

\section{FINITE-ELEMENT MODELLING}

Numerical modelling was undertaken at Imperial College, London, using the program ICFEP (Potts \& Zdravković, 1999).

\section{Soil model}

Some comparative analyses were undertaken using a Mohr-Coulomb type model; however, the analyses undertaken and reported here used Lade's double-hardening cap model (Lade, 1977; Lade \& Nelson, 1987) (see the Appendix). It was generally found that when analyses using both soil models were compared with preliminary test data from the physical models, Lade's cap model provided significantly better predictions of the maximum bending moment than the Mohr-Coulomb type model. The latter overpredicted moments by more than $250 \%$, whereas the former provided predictions similar to the test observations (Fig. 4).

Lade's cap model has been implemented within ICFEP, validated and applied to boundary value problems 
Table 3. Summary of variation in effective anchor stiffness (model dimensions)

\begin{tabular}{|c|c|c|c|c|c|c|c|c|}
\hline \multirow[t]{2}{*}{ Test ID } & \multicolumn{4}{|c|}{ Effective anchor stiffness: $\mathrm{kN} / \mathrm{m} / \mathrm{m}$} & \multicolumn{4}{|c|}{ Anchor loads: kN/m } \\
\hline & Initial $^{*}$ & Revised $^{\dagger}$ & Change & $\begin{array}{l}\text { Effective/ } \\
\text { Theoretical }\end{array}$ & Initial & Final & Test end & Predicted \\
\hline $\begin{array}{l}\text { SPWFG } 13 \\
\text { SPWFG } 14 \\
\text { SPWFG } 15 \\
\text { SPWFG } 16\end{array}$ & $\begin{array}{r}3506 \\
2457 \\
725 \\
791\end{array}$ & $\begin{array}{r}2915 \\
2335 \\
702 \\
707\end{array}$ & $\begin{array}{r}17 \% \\
-5 \% \\
-3 \% \\
-11 \%\end{array}$ & $\begin{array}{l}0 \cdot 40 \\
0 \cdot 32 \\
0 \cdot 10 \\
0 \cdot 10\end{array}$ & $\begin{array}{l}0 \cdot 267 \\
0 \cdot 200 \\
0 \cdot 250 \\
0 \cdot 233\end{array}$ & $\begin{array}{l}1 \cdot 600 \\
1.400 \\
0.750 \\
0.733\end{array}$ & $\begin{array}{l}1 \cdot 89 \\
1 \cdot 85 \\
1 \cdot 12 \\
1 \cdot 07\end{array}$ & $\begin{array}{l}2 \cdot 26 \\
2 \cdot 15 \\
1 \cdot 48 \\
1 \cdot 27\end{array}$ \\
\hline
\end{tabular}

Theoretical anchor stiffness is $7330 \mathrm{kN} / \mathrm{m} / \mathrm{m}$

* Initial effective anchor stiffness suggested by RU Bochum

${ }^{\dagger}$ Revised effective anchor stiffness: see Fig. 3.

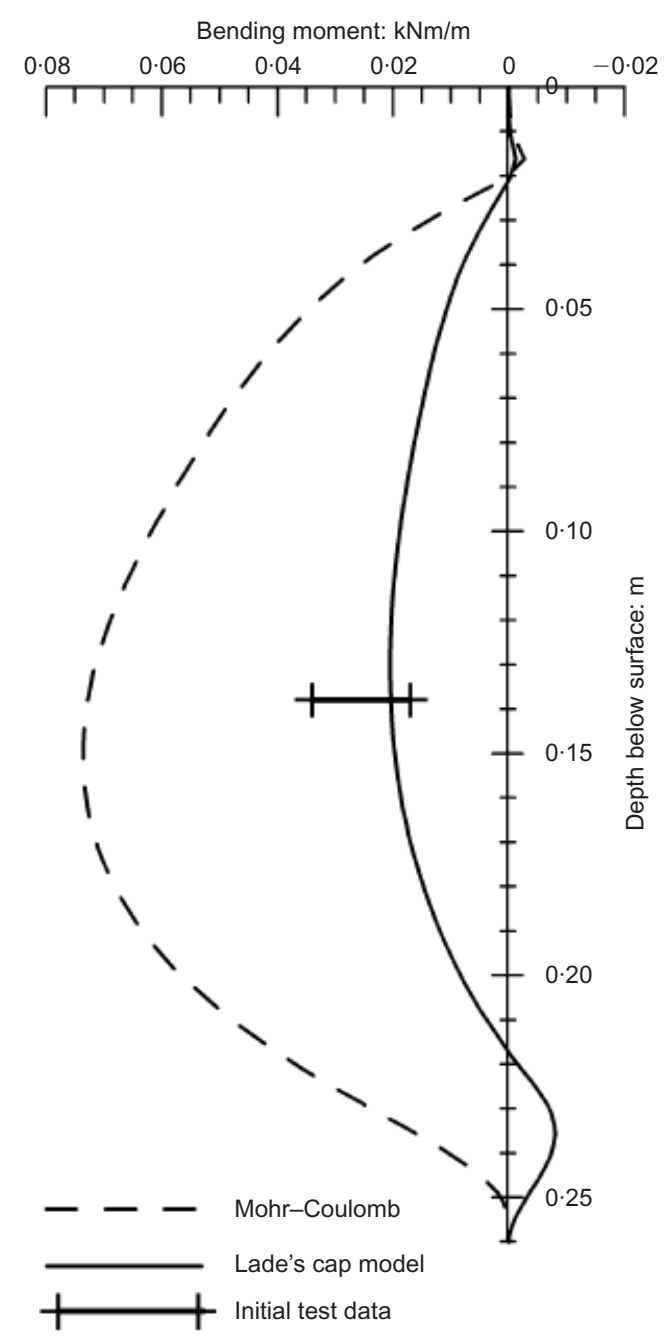

Fig. 4. Effect of soil model (at model scale)

(Kovacević, 1994). In short, the model reproduces many aspects of granular soil behaviour, including the influence of the intermediate principal stress $\sigma_{2}^{\prime}$ on the strength and the stress-strain response (Figs 5 and 6), curvature of the failure envelope, and the suppression of dilation at high confining stresses. While the model has proved to be very powerful, there are some areas where it may not be particularly representative of actual soil response: that is, the intermediate stress effects on the shear strength may be overestimated (van Eekelen, 1980), and there may be a limit to the curvature of the failure envelope and hence the shear strength available at very low pressures (Tatsuoka et al., 1986).
In order to provide suitable parameters for the model, laboratory testing of the sand used in the centrifuge tests was undertaken at RU Bochum, comprising three drained triaxial compression shear tests and two oedometer tests (Table 4). Subsequently, testing comprising isotropic compression tests and triaxial tests over a range of confining stresses of up to $4.5 \mathrm{MPa}$ was also undertaken at Imperial College (Barker, 2001; Fig. 6).

The parameters determined from the Bochum test data were used in the analyses presented here (Bourne-Webb, 2004), on the basis that the element tests were reasonably well reproduced by FEA simulation (Fig. 7). Good accord in terms of mobilised shear strength and volumetric strain response is predicted up to about $8-10 \%$ axial strain. Beyond this point dilation is predicted to continue, whereas in the tests the rate of dilation appears to reduce beyond this point: this would have been due partly to the soil shearing towards a critical state condition and partly because shear bands formed within the test sample. This latter effect resulted in the reported strains, calculated on the basis of the assumption of a uniform sample, being unrepresentative, and it makes it very difficult to validate numerical models in these regions.

The interfaces between the sand and the model wall, and the strongbox walls were modelled with zero-thickness interface elements that use a Coulomb-type model. RU Bochum provided the results of interface shear tests, which indicated a value of interface shearing angle between the sand and aluminium of $26^{\circ}$. Additionally, within the model the interface elements were assigned an angle of dilation of $13^{\circ}$ in order to limit the resistance in these elements to acceptable values, while the normal and shear stiffness values were assumed to be equal and 10 times the value of the average bulk soil stiffness, that is, $K_{\mathrm{N}}=K_{\mathrm{S}}=500 \mathrm{MN} / \mathrm{m}^{3}$ : the choice and potential influence of these latter parameters on the predicted response are discussed by Day \& Potts (1998), who found that the choice of angle of dilation has little effect on the predicted pressures on the wall.

\section{Wall model}

One-dimensional, curved, three-node iso-parametric Mindlin beam elements have been implemented in ICFEP in order to be able to model structural elements (Day, 1990; Potts \& Zdravković, 1999). As part of the implementation of the beam elements, an elasto-plastic constitutive model that allows hardening or softening of the element force parameters to a residual value was included. The form of the model is three-part, piece-wise linear, and the force parameters are uncoupled. For the work discussed here, the beam element constitutive model was modified to allow an increased number of segments to describe the relationship between element forces and strains. 

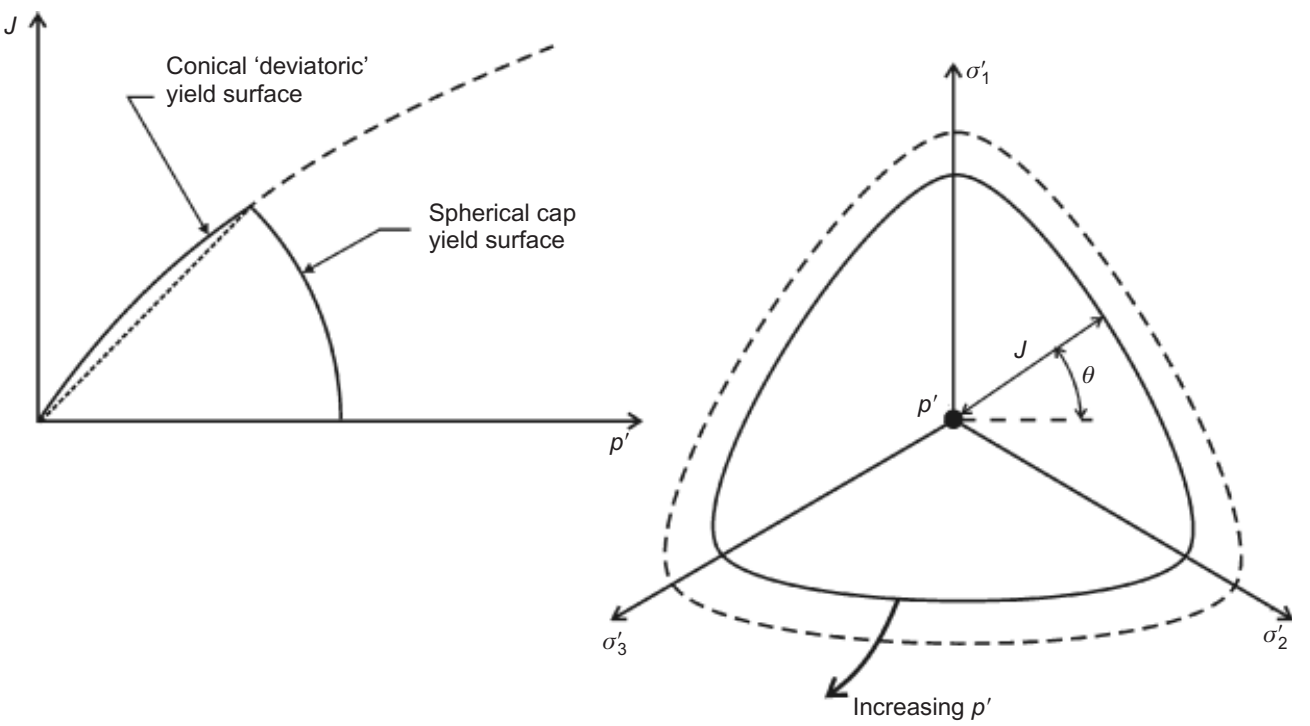

Fig. 5. Schematic of yield surfaces in Lade's cap model

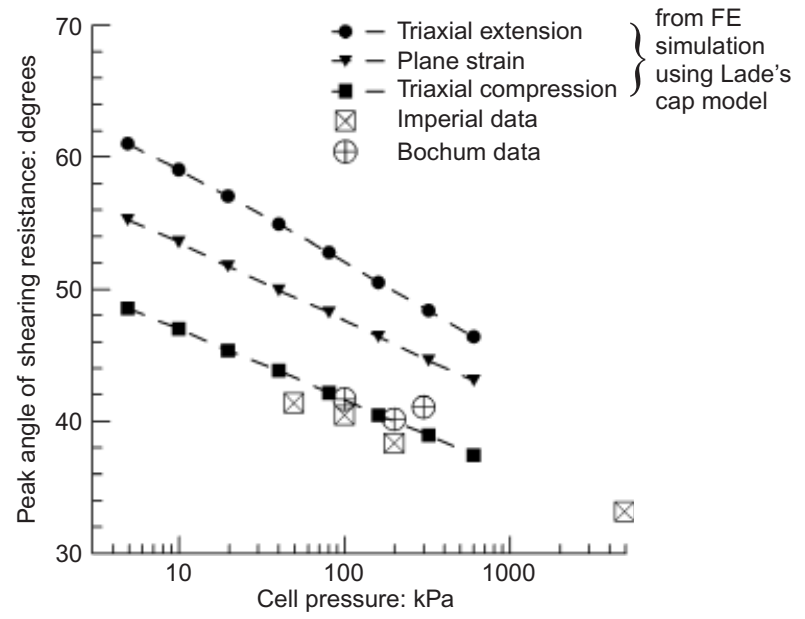

Fig. 6. Effect of intermediate stress

To model the hinge mechanism in the centrifuge tests, beam elements in the notch have been given characteristics appropriate to each particular test. The plastic bending characteristics for the wall sections were supplied by RWTH Aachen, and were based on both physical and numerical simulation of bending tests. Elements over the remainder of the wall are elastic, with properties associated with the full aluminium sheet section (Table 5). The required factors have been incorporated into the revised beam element model in ICFEP and four-point bending tests were simulated numerically to verify that the moment-plastic curvature curves in Fig. 8 can be replicated.

Additionally, some three-dimensional analysis was undertaken to examine the out-of-plane effects such as bending of the waling beam at anchor level. It was found that these effects were small, and the assumption of a two-dimensional response in the test was reasonable (Bourne-Webb, 2004).

\section{Initialisation and boundary conditions}

The geometry for the finite-element mesh is well defined by the strongbox used for the centrifuge modelling, which had internal plan dimensions of $0.63 \mathrm{~m}$ length by $0.36 \mathrm{~m}$ width and $0.41 \mathrm{~m}$ depth. The two-dimensional finite-element mesh used for the analyses is illustrated in Fig. 9.

Initial stresses were based on a coefficient of earth pressure 'at rest', $\mathrm{K}_{0}=\left(1-\sin \phi^{\prime}\right)=0.38$ and a bulk unit weight for the sand of about $16.5 \mathrm{kN} / \mathrm{m}^{3}$. In any case, the application of body forces modifies the initial stress state, in this case to an average value of $K_{0}$ of about 0.34 and with a slightly non-geo-static variation with depth. That is, the horizontal stresses are slightly higher than the equivalent $K_{0}$

Table 4. Lade's double-hardening cap model parameters inferred for Bochum sand

\begin{tabular}{l|l|c}
\hline Stress-strain component & Parameter & Value \\
\hline Elastic parameters & Modulus number, $K_{\mathrm{ur}}$ & 1315 \\
& Elastic exponent, $n$ & 0.512 \\
Spherical 'collapse' yield surface & Poisson's ratio, $\mu$ & $0 \cdot 2$ \\
& Collapse modulus, $C$ & $3.45 \times 10^{-4}$ \\
Deviatoric 'expansive' yield surface & Collapse exponent, $p$ & $0 \cdot 807$ \\
& Failure constant, $\eta_{1}$ & $74 \cdot 41$ \\
& Failure exponent, $m$ & $0 \cdot 246$ \\
& Plastic potential constant, $R$ & 0 \\
& Plastic potential constant, $S$ & 0.527 \\
& Plastic potential constant, $t$ & -2.37 \\
& Work-hardening constant, $\alpha$ & $2 \cdot 618$ \\
& Work-hardening constant, $\beta$ & $-0 \cdot 0112$ \\
& Work-hardening constant, $P$ & 0.132 \\
& Work-hardening exponent, $l$ & 0.976 \\
\hline
\end{tabular}



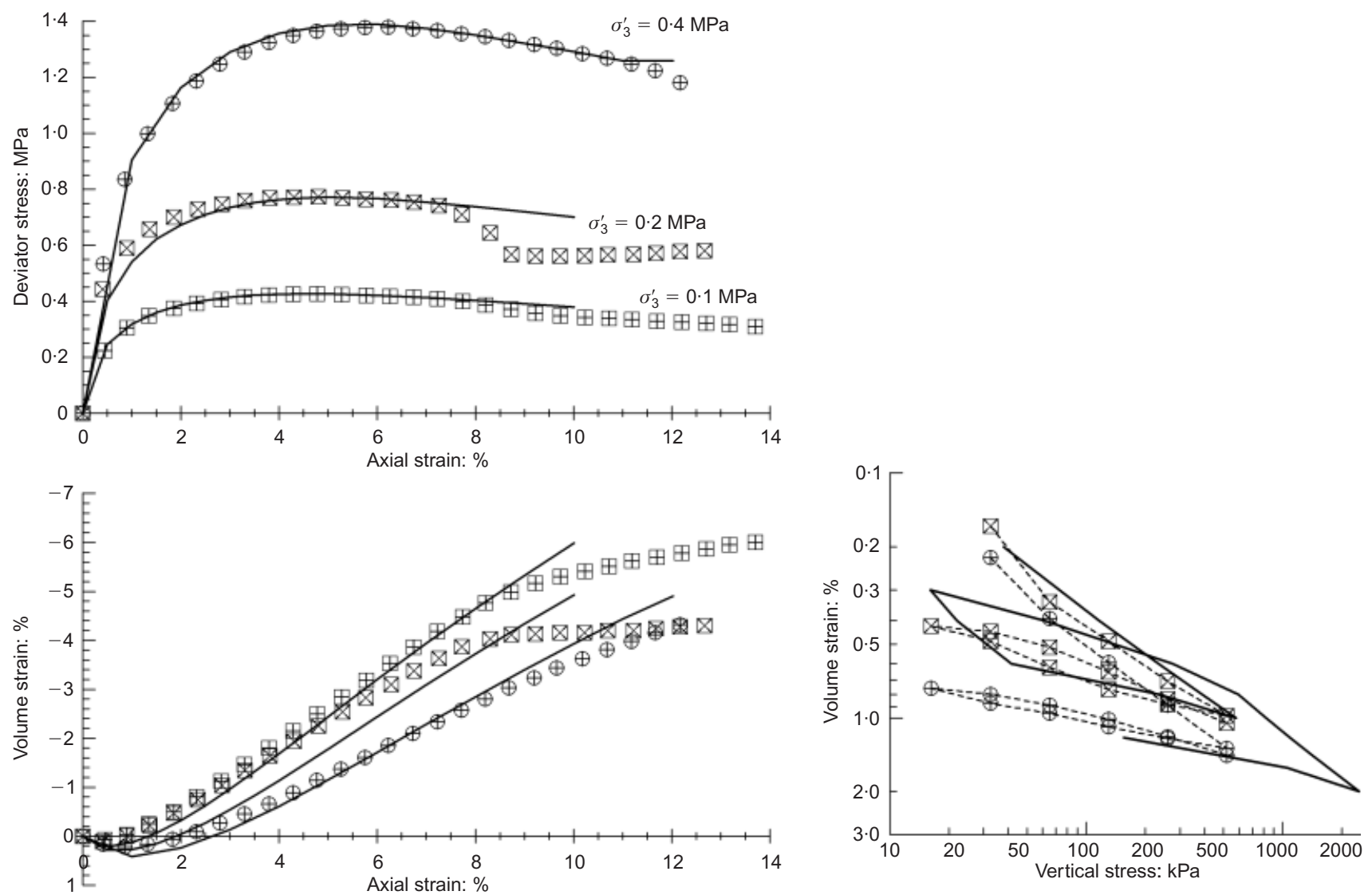

Fig. 7. Validation of Lade's cap model for Bochum sand: symbols, test data; lines, FEA data

Table 5. Section properties for model walls

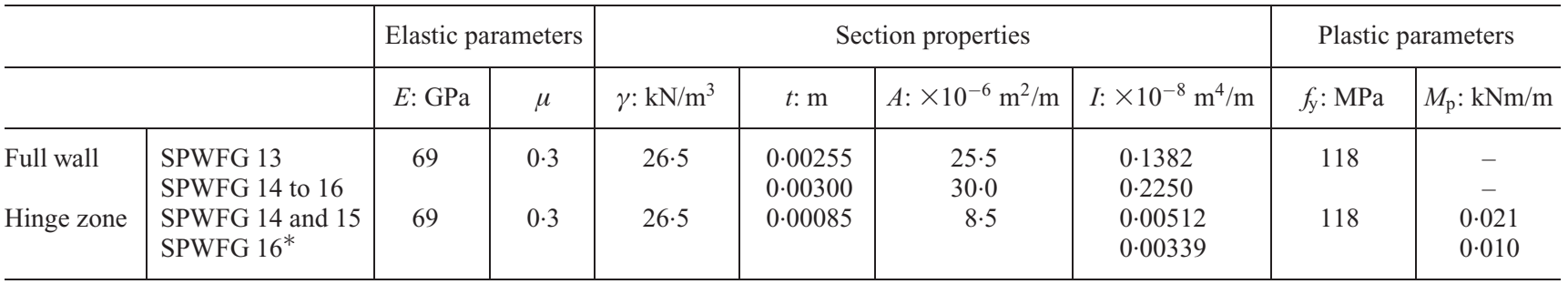

*SPWFG 16: holes bored through wall at hinge level to reduce $M_{\mathrm{p}}$.

$E$, Young's modulus; $\mu$, Poisson's ratio; $\gamma$, bulk density; $t$, wall thickness; $A$, wall cross-sectional area; $I_{x x}$, wall second moment of area; $f_{y}$, yield stress; $M_{\mathrm{p}}$, wall plastic moment.

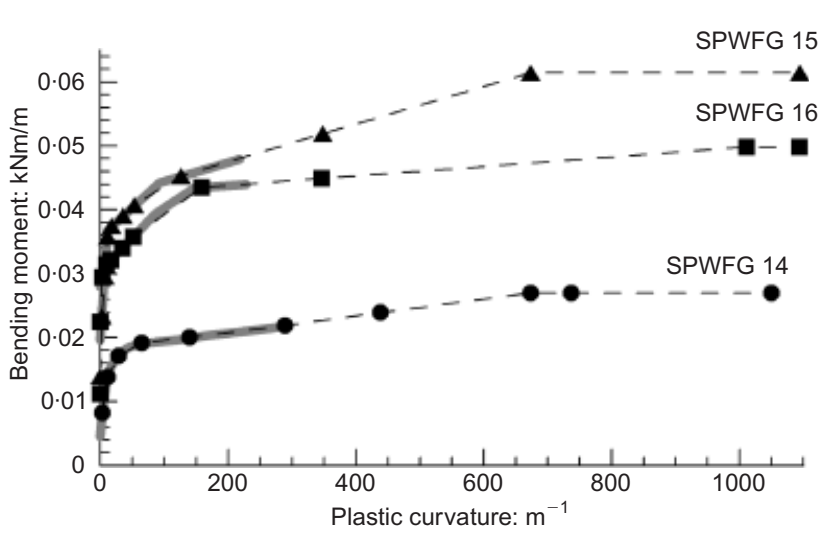

Fig. 8. FEA verification of hinge response (plastic curvature, $\chi_{\mathrm{pl}}$ $=$ total curvature, $\chi_{\text {total }}$, minus elastic curvature, $\left.\chi_{\mathrm{el}}\right)$. Grey line, RWTH data; symbols, FEA simulation condition near the surface and lower at depth - a situation similar to that seen in experiments where the initial stress state has been measured (Garnier, 2002). As the sand was dry, pore water pressures throughout the problem were set to zero.

Displacement boundary conditions were applied in all the analyses, as follows.

(a) All the boundaries representing the strongbox container are fixed in the horizontal direction, and the strongbox base and rear wall boundaries are also fixed in the vertical direction (Fig. 9).

(b) For the bar element used to represent the anchor, initially the end point of the anchor is fixed in the vertical direction only, until such time as the full preload is applied, after which it is also fixed in the horizontal direction. The bar as defined is not attached to the solid elements surrounding it, in order to 


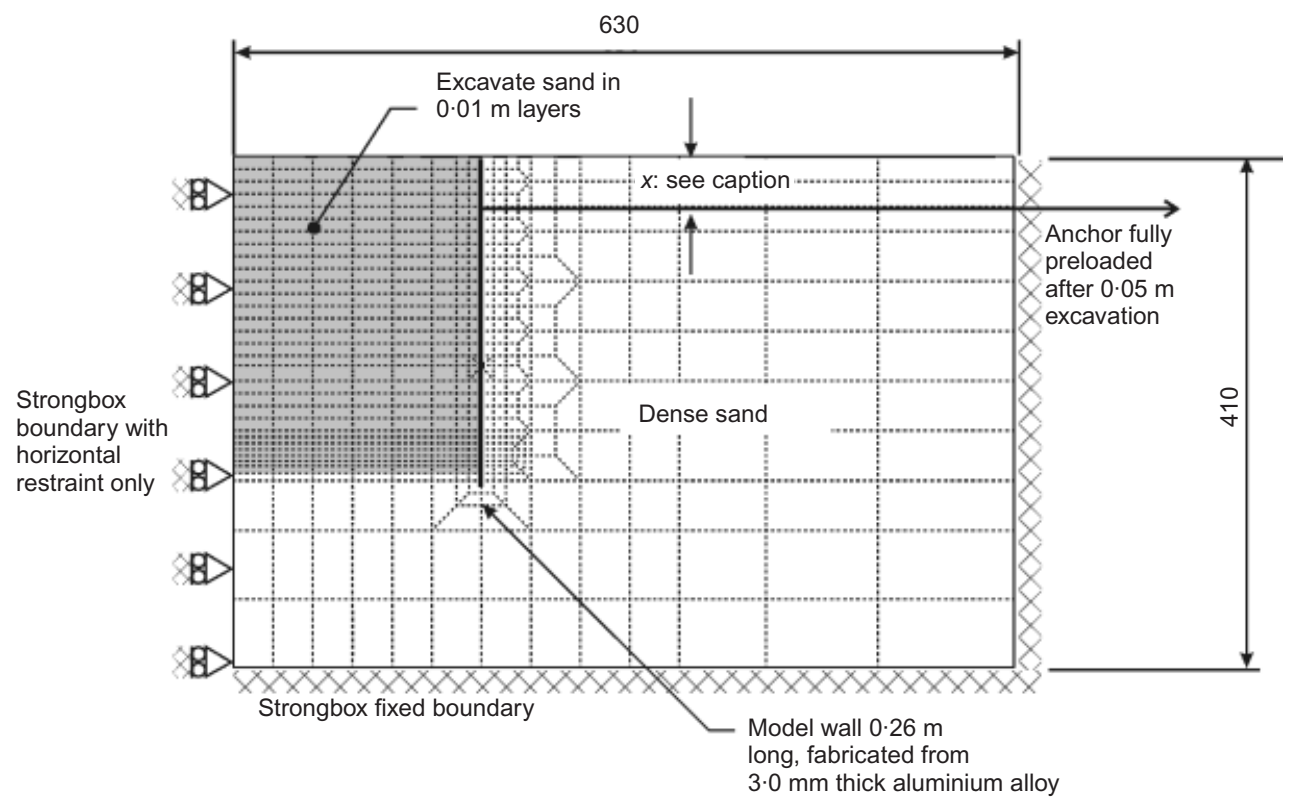

Fig. 9. Mesh geometry for simulation of centrifuge tests. Anchor depth $x=0 \cdot 04 \mathrm{~m}$ for SPWFG 11 to $14 ; 0.018 \mathrm{~m}$ for SPWFG 15 and 16

replicate the test set-up where the anchor passes through a duct.

Load boundary conditions were applied as follows.

(a) In order to replicate the centrifuge test where gravity was increased to about $30 \mathrm{~g}$, vertical body forces have been applied to the entire mesh from an initial stress state (based on $1 \mathrm{~g}$ ), until an equivalent of $30 \mathrm{~g}$ acceleration has been applied.

(b) Prior to the start of excavation, in most of the tests a small preload was applied to the anchor (in the tests this occurred at the same time as the model was accelerated). When the excavation had passed the level of the anchor a further preload increment was applied, as indicated in Table 3.

For the pre-test calculations, either a rigid support was assumed or the bar elements used to represent the anchor were assigned properties on the basis of the theoretical stiffness values. However, it soon became obvious that these were not being mobilised in the tests, and that the anchors were much softer than expected. Therefore, as discussed earlier, the effective values were revised once RU Bochum made the test data available (Table 3 ).

In general, the test sequence modelled for the single anchor tests was as follows.

(a) After initialisation of the mesh with stresses equivalent to $1 \boldsymbol{g}$, body forces are applied incrementally to the model to represent acceleration to $30 \mathrm{~g}$.

(b) An initial preload (Table 3) is applied to the anchor bar element, and excavation then follows, until excavation reaches a level $0.01 \mathrm{~m}$ below the anchor.

(c) The balance of the preload is applied (Table 3), the end of the bar is fixed and further excavation is carried out, until failure of the system is approached.

\section{COMPARISON OF RESULTS FROM TESTS AND \\ ANALYSIS}

Generally, the back-analyses gave reasonable agreement with the maximum bending moment and wall deflection at the hinge zone observed in the test (Figs 10-13). Otherwise, displacements at the toe and head of the wall were not so well replicated, and the bending moment over the anchor was poorly predicted.

Predicted maximum bending moments are generally within about $30 \%$ of the values inferred from the tests, with the back-analysis of test SPWFG 15 almost exactly reproducing the test result. The maximum deflections predicted by the FEA are generally within about $20 \%$ of the observed values, except for SPWFG 16, where the predicted deflection was half the test value. Predicted final anchor forces are typically $20-40 \%$ higher than those recorded in the tests (Table 3). Deflections and moments in the vicinity of the top and bottom of the wall are small in magnitude, and therefore any differences between predictions and observations are exaggerated.

Comparison of the results for tests SPWFG 13 and 14 (Figs 10 and 11; note that results are presented at model scale in all figures) allows the impact of the introduction of a hinge zone in the wall to be evaluated. These tests were based on an anchor at $0.04 \mathrm{~m}$ depth. The main observation from the test results is that the maximum bending moment in SPWFG 14 reduces by about $20 \%$ compared with SPWFG 13. In conjunction with this the anchor load changes very little, reducing by only $2 \%$, and the maximum deflection increases by about $15 \%$, with a distinct discontinuity occurring in the wall at the hinge zone location.

Similar relative effects are predicted by the back-analysis of SPWFG 13 and 14: that is, reduced bending moment $(30 \%)$ and increased maximum deflections (70\%), and very little change in the anchor loads.

In order to increase moment demand in the hinge zone, the anchor depth was reduced in tests SPWFG 15 and 16 (Figs 12 and 13), and hence they are not directly comparable with the earlier tests. Nor are these two tests directly comparable with each other, as the hinge zone in SPWFG 16 had been further modified in an attempt to force plasticity to occur. Holes were drilled through the wall along the line of the notch in the wall at this point, leading to a further reduction in the wall bending stiffness of about $50 \%$.

The wall system in SPWFG 16 reached an ultimate limit state at a shallower excavation depth than in the earlier tests, that is, an equivalent depth of $0.235 \mathrm{~m}$ compared with $0 \cdot 243-0 \cdot 248 \mathrm{~m}$. Subsequent movement of the wall was characterised by large rotations within the hinge zone, and the 


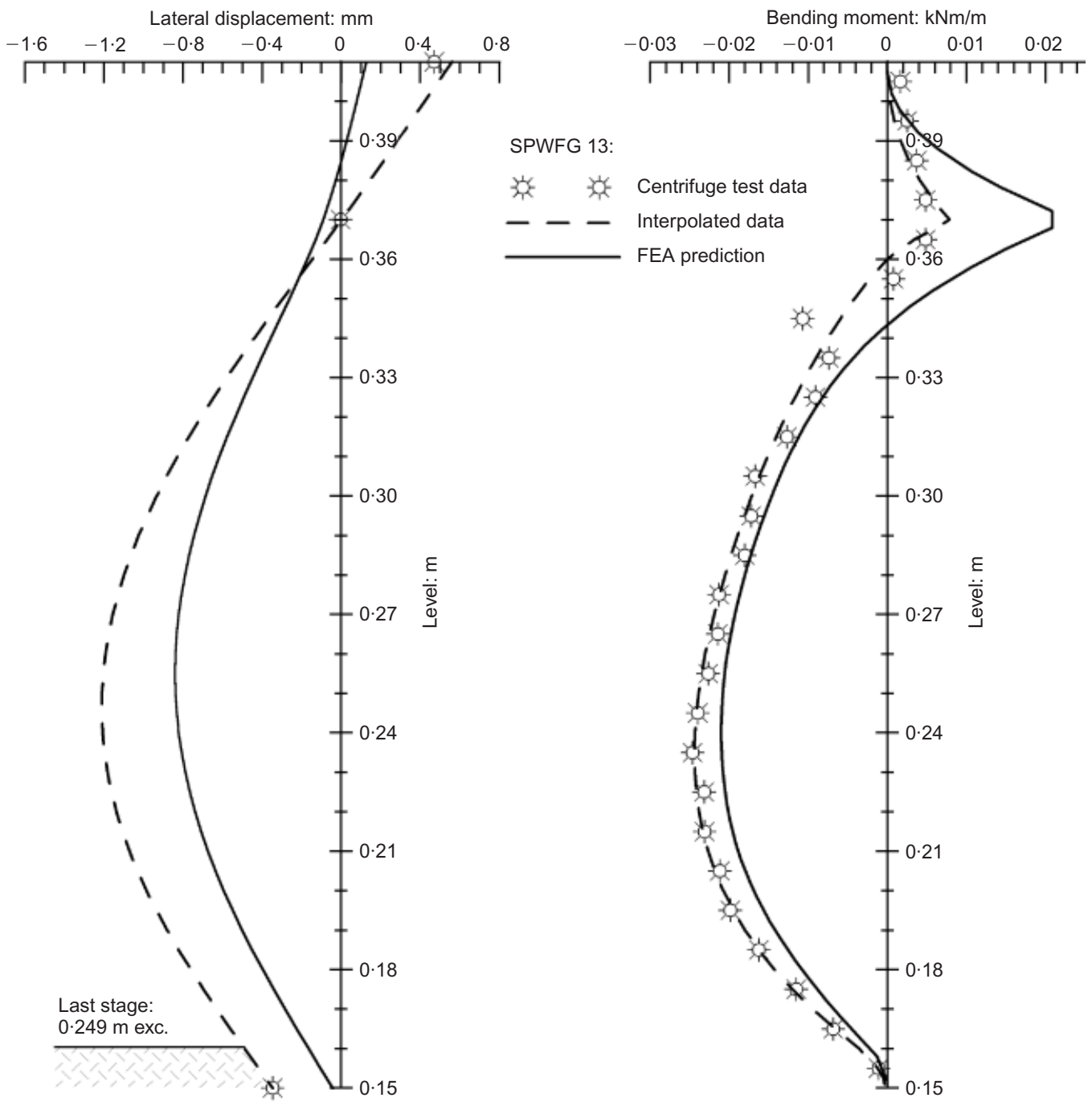

Fig. 10. Comparison of centrifuge test data and FEA results for SPWFG 13

toe of the wall did not move further. This can be compared with the earlier tests SPWFG 14 and 15, where post-failure the deformation of the wall system was a mix of some rotation in the hinge zone and large displacement of the wall's toe into the excavation: that is, failure was dominated by the geotechnical ultimate limit state.

While the initial FE back-analysis for SPWFG 15 gave reasonable agreement with the measured and inferred test results, the comparison of the predictions for SPWFG 16 appears to be rather poor, particularly the magnitude and shape of the bending moment envelope.

\section{DISCUSSION}

In order to facilitate the centrifuge testing, certain compromises had to be made that directly affected the usefulness of the tests in terms of the aims of the study. The use of a notched wall to provide a plastic hinge zone was perhaps the most significant compromise. However, there were also variations in the execution of each test that limited the extent to which they could be compared: changes in anchor level, variation in effective anchor stiffness, modifications to the hinge zone and reuse of the wall. This last factor meant that the moment-plastic curvature response in each wall test was slightly different, because of hardening of the aluminium as it was bent and re-straightened.

The impact of changes in wall flexibility is demonstrated in Fig. 14 when comparing tests SPWFG 13 and 14, and to a lesser extent SPWFG 15 and 16, where the ratio of moment demand, $M$ (either observed in the test or predicted by the FEA), to the equivalent limit equilibrium estimate of bending moment, $M^{\mathrm{LE}}$, is plotted relative to the flexibility of the wall system, $\rho^{*}$.

The moment $M^{\mathrm{LE}}$ was estimated on the basis of a calculation using the method outlined in the draft for Eurocode 7 , ENV 1997-1 (BSI, 2004) The evaluation of $\rho^{*}$ is that defined by Potts \& Bond (1994) that revised the original flexibility coefficient, $\rho$, defined by Rowe (1952)

$$
\rho^{*}=\frac{H^{4} E_{\text {soil }}}{E I}
$$

where $H$ is the wall depth of embedment, $E_{\text {soil }}$ is the average soil stiffness over the wall length, $E$ is the wall Young's modulus and $I$ is the wall second moment of area. In all the tests there is a reduction in moment demand with increasing wall flexibility, and hence projections made from the original tests using an intact wall section gave a false target moment demand for the later tests with a hinge zone in the wall. The moment-reduction effect in the numerical predictions is marginally stronger than the test observations.

Moment demand was determined by way of strain measurements on the intact wall either side of the hinge zone, and was interpolated to obtain a value in the hinge. Rotation within the hinge was not measured directly; however, it was possible to estimate approximate wall rotation and hence curvature from measured displacements using the methods 


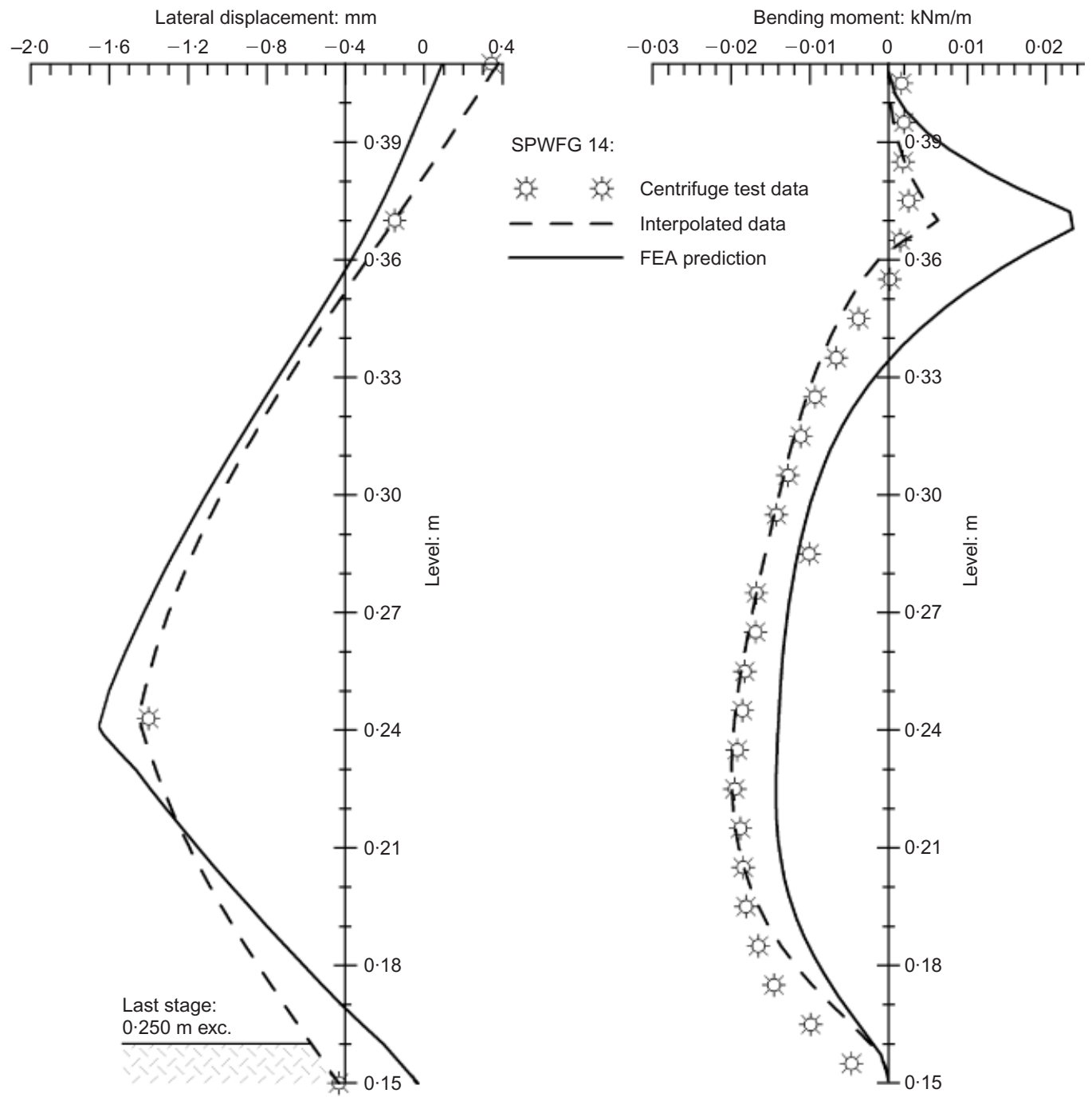

Fig. 11. Comparison of centrifuge test data and FEA results for SPWFG 14

outlined in Eurocode 7 ENV 1997-1. The moment demand and associated curvature values at the end of test are compared with the $M-\chi$ relationship specified for each test, and the response predicted by the analysis, in Fig. 15.

Apparent inconsistencies between the moment demand and plastic curvature reported for the tests become apparent when comparing the moment-plastic curvature characteristics that were specified for each test, for use in the numerical analyses (Fig. 15). Only test SPWFG 16 developed moment-curvature behaviour broadly compatible with the specified characteristic for the test; it is probably significant that SPWFG 16 was the last of the single-anchor wall tests and hence was on a virgin hardening curve in terms of the moment-curvature response.

Referring to the test data and numerical predictions for SPWFG 16, it is apparent that there are some discrepancies. In particular, the bending moment data show a discontinuity in the region of the hinge, with the two data points immediately either side of the hinge zone suggesting moments about 20\% less than the next set to either side (Fig. 13). These localised values have been compared with maximum values in Figs 14 and 15. The maximum value is not compatible with the increase in wall flexibility between SPWFG 15 and 16, but is apparently compatible with the specified moment-curvature characteristic for SPWFG 16. These anomalous results are attributed to the drilling of holes to reduce the wall flexibility for test SPWFG 16, and probable work-hardening of the aluminium in the vicinity of the hinge zone. It is interesting to note that the analysis predicts a moment demand at the hinge similar to that suggested by the measurements local to the hinge zone, although the analysis does not predict the development of plastic curvature as significant as that suggested by the test.

In the case of the other two tests, SPWFG 14 and 15, the plastic curvature inferred for the test differs significantly from that specified for the relevant analysis. While the moment demand inferred from the test and that predicted by the FEA are comparable, the associated curvatures for the test results do not lie on the specified moment-curvature characteristic, most probably as a consequence of uncertainty in what the correct characteristic might be, owing to reuse of the wall section.

The numerical analyses presented here used a soil model for which the parameters were derived directly and unmodified from simple laboratory tests and, once the variable factors in each test were quantified, yielded surprisingly good agreement with the test data. Further differences were introduced into the comparison between the test and FEA results owing to the overprediction of resistance above the upper anchor, particularly in SPWFG 13 and 14 when the anchor was deeper, and in the passive zone in front of the wall. This is probably an effect of possible overprediction of resistance, at low confining pressures and on extension unloading-type stress paths, and the isotropic nature of the model, which remains elastic during unloading until plasticity is mobilised again on the extension yield surface. As a 

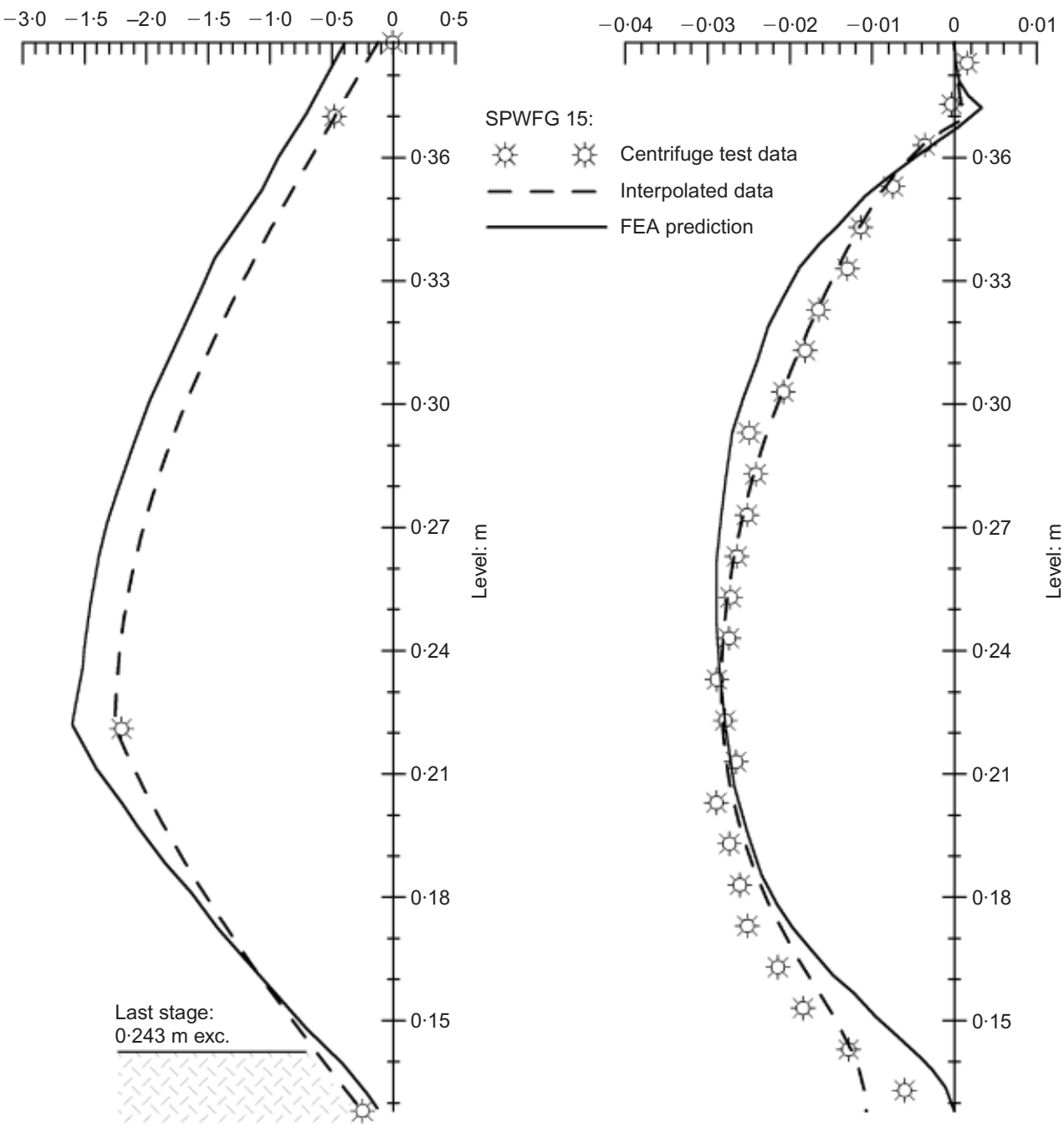

Fig. 12. Comparison of centrifuge test data and FEA results for SPWFG 15

consequence, the comparison between test observations (displacements, moment demand and anchor loads) at the head and toe of the wall and numerical predictions of behaviour in the same areas is poor. It is also possible that friction effects on the anchor where it passed through the test specimen may have led to under-measurement of the mobilised anchor force at the load transducer that was located at the rear of the centrifuge strongbox.

\section{CONCLUSIONS}

The aims for the centrifuge testing were twofold: (a) to investigate the effect of wall plasticity on the response of varying wall system geometries; and (b) to provide physical data against which calculation methods could be validated.

As a consequence of the compromises made in order to facilitate the centrifuge testing, and modifications made during the testing, plasticity was not consistently developed in the wall system. This is due to the following factors.

(a) The notch used in the hinge zone reduced the effective bending stiffness of the wall by a factor of about 40 compared with the intact wall section.

(b) The wall section was used repeatedly, with a different moment-curvature characteristic applicable in each test.

(c) The variation in apparent anchor stiffness from test to test may also have had some impact.

These factors led to the tests with a hinge zone present having produced reductions in moment demand additional to those due to the intrinsic flexibility of the intact aluminium sheet used to form the model. This additional reduction in moment demand is due to the increased displacement of the wall and the pressure redistribution associated with the local reduction in wall stiffness created by the introduction of a notch along the wall.

The reduction of moment demand and the ability for significant earth pressure redistribution due to 'arching' constitute a well-known effect (Rowe, 1952). However, preliminary calculations demonstrably underestimated the reduction in moment demand resulting from the introduction of the hinge zone. This was due to the use of a MohrCoulomb-type soil model which has been demonstrated to underpredict earth pressure redistribution, and a smaller differential between the bending stiffness of the intact wall and the hinge zone - that is, a factor of about 3 rather than 40 as in the tests reported here.

The notch was intended to create a mechanism of wall deformation similar to that associated with a plastic hinge, so that the impact of large plastic rotation on the response of an embedded retaining wall could be examined. However, the presence of the weakened zone from the outset of the test and its associated impact have compromised this assessment. In reality, the mechanism of hinge formation and associated wall deformation differs: prior to plastic hinge formation in the SSP, almost the full elastic wall bending stiffness would be available up until first yield; only then 


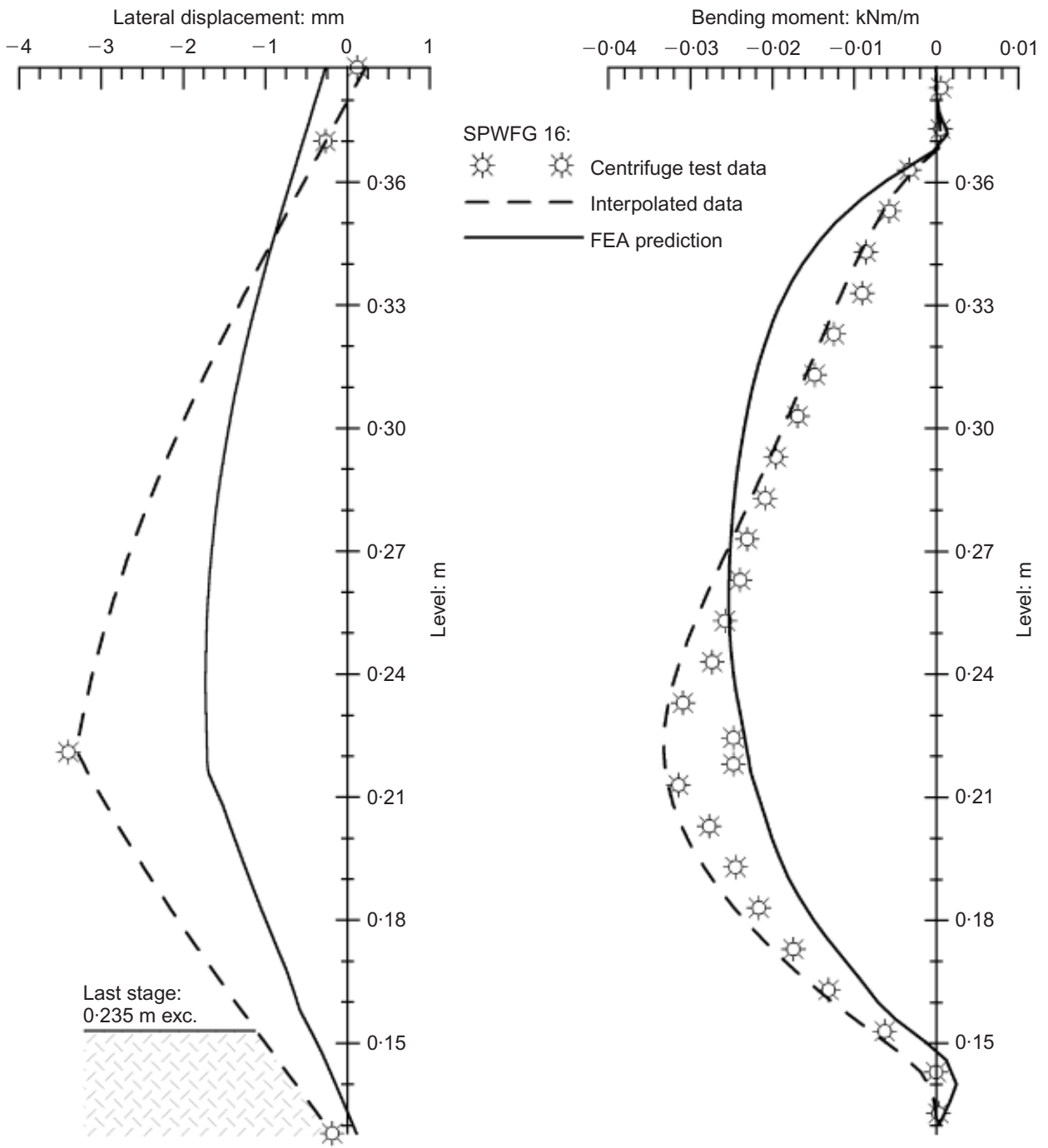

Fig. 13. Comparison of centrifuge test data and FEA results for SPWFG 16

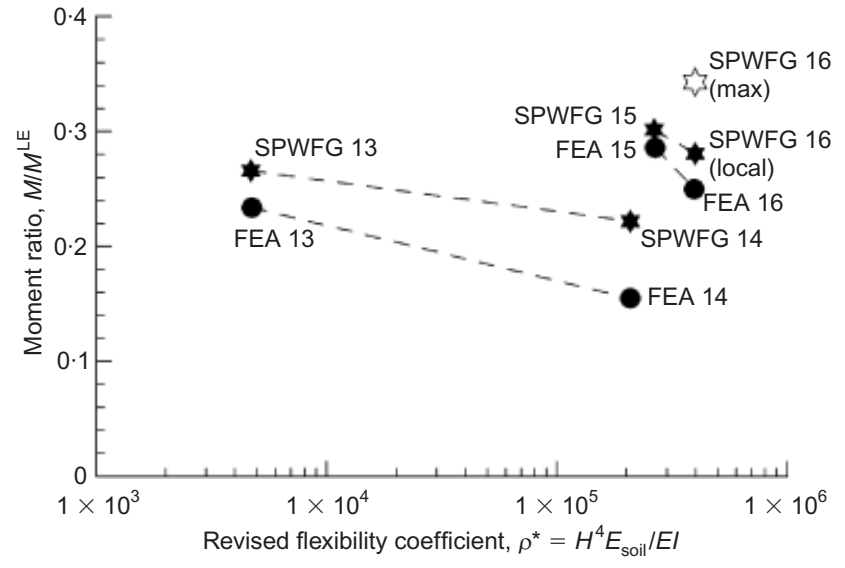

Fig. 14. Impact of wall flexibility variation

would wall flexibility start to increase, with possible further earth pressure redistribution. In any case, in dry sand the development of wall plasticity in the SSP was subsequently proved difficult to demonstrate owing to the high potential for earth pressure redistribution due to the flexibility of realistic sheet pile sections (Bourne-Webb, 2004).

In terms of the second aim, the physical testing in the centrifuge has been more useful. The FE analysis, while not entirely reproducing the response measured or inferred from the tests, did seem to be consistent within itself, and provided at least the correct form of response when compared with the physical test data. The potential for obtaining good agreement between the test observations and the FE calculations may have been compromised by various factors, including the following.

(a) During the test programme different measures were implemented in order to either increase the load on the wall (reduced anchor depth) or reduce the stiffness of the hinge zone (stitch drilling along line of notch), and so promote failure within the hinge zone. This process of incremental changes in each test meant that there were no directly comparable tests to prove the repeatability of the test procedures used.

(b) The tests were complex. This complexity resulted from the aim of reproducing a realistic construction process, that is, excavation and anchor tensioning while in flight, and the large number of variables or unknowns introduced as a result.

(c) There was a need for information from the completed tests, that is, details of the load-displacement characteristic for the anchors, and the wall momentcurvature characteristic for each test.

(d) Some details of the FE calculations, including:

(i) variation of the load-extension relationship for the anchors between tests and the non-linearity of response 


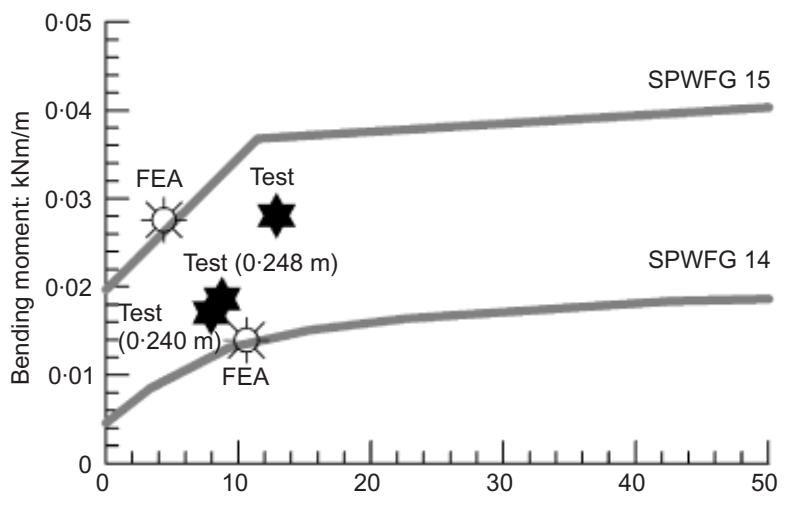

(a) Isotropic, minor principal stress-dependent elasticity based on the unloading modulus $E_{\mathrm{ur}}$ and Poisson's ratio $\mu$. As an alternative formulation, the minor principal stress $\sigma_{3}^{\prime}$ may be replaced by the mean effective stress $p^{\prime}$. It was found that under certain load cycles the original formulation (equation (1)) is non-conservative with respect to energy, and a revised formulation (equation (2)) has been developed (Lade \& Nelson, 1987).

$$
\begin{aligned}
& E=K_{\text {ur }} p_{\mathrm{a}}\left(\frac{\sigma_{3}^{\prime}}{p_{\mathrm{a}}}\right)^{n} \\
& E=M_{\mathrm{R}} p_{\mathrm{a}}\left[\left(\frac{I_{1}}{p_{\mathrm{a}}}\right)^{2}+6 J_{2} \frac{1+\mu}{(1-2 \mu) p_{\mathrm{a}}^{2}}\right]
\end{aligned}
$$

where

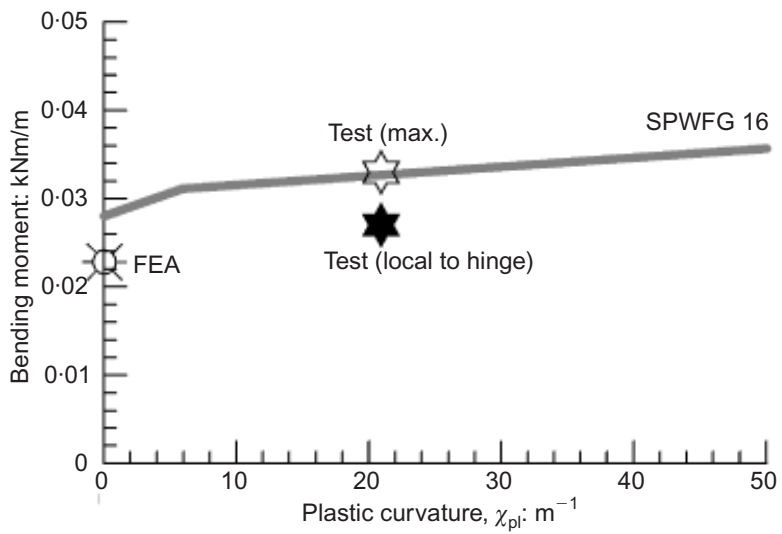

$$
\begin{aligned}
I_{1} & =\sigma_{1}^{\prime}+\sigma_{2}^{\prime}+\sigma_{3}^{\prime} \\
& =3 p^{\prime} \\
J_{2} & =\frac{\left(\sigma_{1}^{\prime}-\sigma_{2}^{\prime}\right)^{2}+\left(\sigma_{2}^{\prime}-\sigma_{3}^{\prime}\right)+\left(\sigma_{3}^{\prime}-\sigma_{1}^{\prime}\right)}{6} \\
& =J^{2}
\end{aligned}
$$

(b) Plastic 'collapse' strains described by a spherical cap yield surface that is centred on the origin for principal stress space, and for which the required relationships are developed on the basis of the response of the soil undergoing isotropic compression. Irrecoverable strains occur during isotropic compression, and because the stress path is on the hydrostatic axis, no, or negligible, plastic 'expansive' (shear) strains occur. Hence the total strains that occur, $[\partial \varepsilon]^{\text {iso }}$, are due to a combination of elastic $\left[\partial \varepsilon^{\mathrm{e}}\right]$ and plastic 'collapse' (volumetric) strains: that is, $\left[\partial \varepsilon^{\mathrm{c}}\right]=[\partial \varepsilon]^{\text {iso }}-\left[\partial \varepsilon^{\mathrm{e}}\right]$.

$$
\begin{aligned}
& F_{\text {cap }}=I_{1}^{2}+2 I_{2}-f_{\mathrm{c}}=0=G_{\text {cap }} \\
& I_{2}=-\left(\sigma_{1}^{\prime} \sigma_{2}^{\prime}+\sigma_{2}^{\prime} \sigma_{3}^{\prime}+\sigma_{3}^{\prime} \sigma_{1}^{\prime}\right) \\
& =J_{2}-3 p^{\prime 2}
\end{aligned}
$$

The spherical yield surface $F_{\text {cap }}$ and the plastic potential $G_{\text {cap }}$ describing the incremental strain vector are, necessarily, associated. This is to ensure that the strain increment vector is coincident with the hydrostatic axis $\left(\sigma_{1}^{\prime}=\sigma_{2}^{\prime}=\sigma_{3}^{\prime}\right)$ during isotropic compression. Mobilisation of the spherical cap will result in irrecoverable volume changes, or compaction of the soil structure with increasing stress, but will not lead to failure of the soil.

(c) A failure criterion that forms a rounded triangle in the deviatoric $(J-\theta)$ plane is dependent on the intermediate principal stress $\left(\sigma_{2}^{\prime}\right)$, and incorporates curvature of the failure envelope at low stresses in the triaxial $\left(p^{\prime}-J\right)$ plane.

$$
\begin{aligned}
& \left(\frac{I_{1}^{3}}{I_{3}}-27\right)\left(\frac{I_{1}}{p_{\mathrm{a}}}\right)^{m}=\eta_{1} \\
& I_{3}=\sigma_{1}^{\prime} \sigma_{2}^{\prime} \sigma_{3}^{\prime} \\
& \quad=p^{\prime 3}-p^{\prime 2} J-4 J^{3}\left[\frac{(1 / 2+\cos 2 \theta) \sin \theta}{3 \sqrt{3}}\right]
\end{aligned}
$$

(d) Plastic 'expansive' strains that are described by a curved conical yield surface $F_{\mathrm{dev}}$, of the same shape as the failure envelope, with its apex at the origin of principal stress space. The plastic potential surface $G_{\mathrm{dev}}$ has the same shape as the yield surface in the deviatoric plane, but is non-associated, and therefore has a similar but slightly different shape in the $\left(p^{\prime}-J\right)$ plane.

$$
\begin{aligned}
& F_{\mathrm{dev}}=\left(\frac{I_{1}^{3}}{I_{3}}-27\right)\left(\frac{I_{1}}{p_{\mathrm{a}}}\right)^{m}-f_{\mathrm{p}}=0 \\
& G_{\mathrm{dev}}=I_{1}^{3}-\left[27+\eta_{2}\left(\frac{p_{\mathrm{a}}}{I_{1}}\right)^{m}\right] I_{3}
\end{aligned}
$$

In this case the total strains that occur, $[\partial \varepsilon]^{\text {tot }}$, are due to a combination of elastic strains $\left[\partial \varepsilon^{\mathrm{e}}\right]$, plastic 'collapse' strains $\left[\partial \varepsilon^{\mathrm{c}}\right]$, and plastic 'expansive' strains: that is, $\left[\partial \varepsilon^{\mathrm{p}}\right]=[\partial \varepsilon]^{\text {tot }}-$ non-linear elasticity and isotropic work-hardening/softening plasticity theory. The essential features of the model include the following. 
$\left[\partial \varepsilon^{\mathrm{e}}\right]-\left[\partial \varepsilon^{\mathrm{c}}\right]$. The decision as to whether either of $\left[\partial \varepsilon^{\mathrm{c}}\right]$ or $\left[\partial \varepsilon^{\mathrm{p}}\right]$ or both occur depends on the stress path direction, and on which of the yield surfaces are engaged.

The yield surface relationship work-hardens $\left(W=\int\left\{\sigma_{i j}\right\}^{\mathrm{T}}\left\{\varepsilon_{i j}\right\}\right)$ to a peak value, defined by the failure condition, and is then able to work-soften during straining post-peak. However, the work-softening relationship reduces to zero strength, rather than some finite value that would yield a critical or constant-volume state, so the relationship is valid only over a limited range of strain in the post-peak region. This feature of the model has not previously been noted in the literature, and a modification to override this has been developed (Bourne-Webb, 2004). Lade's cap model has been implemented, validated and applied to boundary value problems (Kovacević, 1994). Three versions for the elasticity relationship have been included: that is, $\sigma_{3}^{\prime}$ or $p^{\prime}$ dependent, and the modified energyconserving formulation.

During implementation of the model it was found that the procedure described by Lade \& Nelson (1987) did not meet the consistency condition for plastic flow associated with the conical yield surface. This was because some of the 'constants' in the yield surface and plastic potential relationships were in fact dependent on the minor principal stress. Therefore the derivatives of the yield and plastic potential functions had to be corrected before the model could be implemented (Kovacević, 1994).

\section{NOTATION}

$A$ cross-sectional area

$C$ collapse modulus

E Young's modulus

$E_{\text {soil }}$ average soil stiffness over wall length

$F_{\text {cap }}$ spherical yield surface

$F_{\text {dev }}$ conical yield surface

$f_{\mathrm{c}}$ cap function

$f_{\mathrm{p}}$ failure function

$f_{\mathrm{y}}$ yield stress

$G_{\text {cap }}$ plastic potential

$G_{\text {dev }}$ plastic potential surface

$g$ gravitational acceleration

$H$ wall length

$I, I_{x x} \quad$ wall second moment of area

$I_{1}, I_{2}, I_{3}$ stress invariants

$J_{1}, J_{2}$ deviatoric stress invariants

$K_{\mathrm{N}}$ interface normal stiffness

$K_{\mathrm{S}}$ interface shear stiffness

$K_{\text {ur }}$ modulus number

$\mathrm{K}_{0} \quad$ at-rest earth pressure coefficient

$L$ length of tie between wall and anchor point

$l$ work-hardening exponent

$M$ moment demand/bending moment

$M^{\mathrm{LE}} \quad$ limit equilibrium estimate of bending moment

$M_{\mathrm{p}} \quad$ wall plastic moment

$M_{\mathrm{R}}$ revised modulus number

$m$ failure exponent

$n$ elastic exponent

$P \quad$ work-hardening constant

$p$ collapse exponent

$p^{\prime}$ mean effective stress

$p_{\text {a }}$ atmospheric pressure

$R, S, t$ plastic potential constants

$t$ wall thickness

$W$ work-hardening function

$\left[\partial \varepsilon^{\mathrm{c}}\right]$ plastic 'collapse' (volumetric) strain

$\left[\partial \varepsilon^{\mathrm{e}}\right]$ elastic strain

$\left[\partial \varepsilon^{\mathrm{p}}\right]$ plastic 'expansive' strain

$[\partial \varepsilon]^{\text {iso }}$ total strain

$[\partial \varepsilon]^{\text {tot }}$ total strain

$\alpha, \beta$ work-hardening constants

$\gamma$ density $\varepsilon_{i j} \quad$ strain vector

$\varepsilon_{\mathrm{v}}$ volumetric strain

$\eta_{1} \quad$ failure constant

$\eta_{2}$ plastic potential constant

$\theta$ Lode's angle

$\mu$ Poisson's ratio

$\rho$ wall flexibility coefficient

$\rho^{*} \quad$ flexibility of wall system

$\sigma_{i j} \quad$ stress vector

$\sigma_{1}^{\prime}, \sigma_{2}^{\prime}, \sigma_{3}^{\prime}$ principal stresses

$\sigma_{\mathrm{v}}^{\prime} \quad$ vertical effective stress

$\phi^{\prime}$ angle-of-shearing resistance

$\chi_{\mathrm{el}}$ elastic curvature

$\chi_{\mathrm{pl}}$ plastic curvature

$\chi_{\text {total }}$ total curvature

\section{REFERENCES}

Barker, C. A. (2001). Behaviour of sand: an investigation of Bochum sand. MSc dissertation, Imperial College, University of London.

Bourne-Webb, P. J. (2004). Ultimate limit state analysis for embedded retaining walls. $\mathrm{PhD}$ thesis, Imperial College, University of London.

Bourne-Webb, P. J, Potts, D. M., Godden, S. \& Rowbottom, D. (2006). Elastic-plastic flexure of embedded retaining walls. Proc. 6th Int. Conf. Numerical Methods in Geotechnical Engineering, Graz.

Bourne-Webb, P. J, Potts, D.M. \& Rowbottom, D. (2007). Plastic bending of steel sheet piles. Proc. Instn Civ. Engrs Geotech. Engng 160, No. 3, 129-140.

BSI (2004). BS ENV 1997-1, Eurocode 7: Geotechnical design, Part 1-General rules. Milton Keynes: British Standards Institution.

Day, R. A. (1990). Finite element analysis of sheet pile retaining walls. PhD thesis, Imperial College, University of London.

Day, R. A. \& Potts, D. M. (1998). The effect of interface properties on retaining wall behaviour. Int. J. Numer. Anal. Methods Geomech. 22, No. 12, 1021-1033.

Garnier, J. (2002). Properties of soil samples used in centrifuge tests. Physical modeling in Geotechnics: ICPMG '02, St Johns, Newfoundland, 5-19

König, D. (2002). Modeling of deep excavations. Proc. Int. Conf. on Physical Modeling in Geotechnics: ICPMG '02, St Johns, Newfoundland, 83-88.

Kovacević, N. (1994). Numerical analyses of rockfill dams, cut slopes and road embankments. $\mathrm{PhD}$ thesis, Imperial College, University of London.

Lade, P. V. (1977). Elasto-plastic stress-strain theory for cohesionless soil with curved yield surfaces. Intl J. Solids Struct. 13, No. $11,1019-1035$.

Lade, P. V. \& Nelson, R. B. (1987). Modelling the elastic behaviour of granular materials. Int. J. Numer. Anal. Methods Geomech. 11, No. 5, 521-542.

Potts, D. M. \& Bond, A. J. (1994). Calculation of structural forces for propped retaining walls. Proc. 13th Int. Conf. Soil Mech. Found. Engng, New Delhi, 823-826.

Potts, D. M. \& Zdravković, L. (1999). Finite element analysis in geotechnical engineering: Theory. London: Thomas Telford.

Rowe, P. W. (1952). Anchored sheet-pile walls. Proc. Instn. Civ. Engrs, London, Part 1 1, 27-70; Discussion, 616-647.

Tatsuoka, F., Sakamoto, M., Kawamura, T. \& Fukushima, S. (1986). Strength and deformation characteristics of sand in plane-strain compression at extremely low pressures. Soils Found. 26, No. 1, 65-84.

van Eekelen, H. A. M. (1980). Isotropic yield surfaces in three dimensions for use in soil mechanics. Int. J. Numer. Anal. Methods Geomech. 4, No. 1, 89-101. 